\title{
How should substance use problems be handled? Popular views in Sweden, Finland, and Canada
}

Jan Blomqvist, Anja Koski-Jännes and John Cunningham

\author{
Jan Blomqvist is a Professor, \\ based at Centre for Social \\ Research on Alcohol and \\ Drugs (SoRAD), Stockholm \\ University, Stockholm, \\ Sweden. \\ Anja Koski-Jännes is a \\ Professor, based at School of \\ Social Sciences and \\ Humanities, University of \\ Tampere, Tampere, Finland. \\ John Cunningham is a \\ Professor, based at Centre for \\ Mental Health Research, The \\ Australian National University, \\ Canberra, Australia.
}

\begin{abstract}
Purpose - Although the way in which, for example, substance use problems are conceived and reacted to (by experts and treatment professionals but also by the environment), can have vast consequences for those directly or indirectly concerned, there is little systematic knowledge about how various preferred approaches differ between types of problems and sociocultural settings. In an ambition to at least partly mend this gap, this paper aims to compare how the general public in Sweden, Finland, and Canada appraise four generically different approaches to dealing with substance use problems, as these are applied to problem use of alcohol, cannabis, heroin, and cigarettes.

Design/methodology/approach - The paper uses data from three national surveys, aimed at uncovering how representative population samples from Sweden, Finland, and Canada perceive and understand the character of, and the proper way of handling, various addictive problems. Data from these surveys have been used to discern and operationalize four basic "models of helping and coping" as these have been outlined by Brickman et al. (1982). The analysis has aimed at investigating how the popular preferences for either of these models vary with type of addiction (to cigarettes, alcohol, cannabis, and other ("hard") drugs, national setting, and potentially important respondent characteristics.

Findings - The results point to large differences between the ways in which the general public understands the proper way of handling the four types of addiction, and shows, for example, that addiction to "hard" drugs is predominantly perceived as a matter for expert treatment, whereas smoking, or addiction to cigarettes, is more often perceived as a bad habit which the user is able to break on her/his own. In addition, the popularity of different handling models is found to vary between countries, and with personal characteristics such as gender, age, and substance use experiences.

Originality/value - The study is one of few that have systematically tried to find out how various forms of substance use problems, or addiction, are conceived and reacted to in various national and social settings.

Keywords Handling models, National comparisons, Substance use problems

Paper type Research paper

\section{Background \\ Introduction}

The ways, in which the use of various mind altering substances have been judged and reacted to, has varied with cultures and historical times. According to many, the extent to which someone's substance use is likely to get them into inconveniences, and evolve into what is regarded as an "abuse" or an "addiction", may not only depend on the pharmacological properties of the drug in question, or the neuropsychological characteristics of the user, but also to a large extent on the reactions with which the user is met, by the environment and by society at large. By applying Hacking's (1999) ideas about social construction, addiction could be seen as an "interactive kind", i.e. a phenomenon, the official and predominant definition of which influences the self-definitions and behaviours of those defined, thereby serving, to an extent, as
\end{abstract}


a self-fulfilling prophecy. In spite of the potentially vast consequences of such culturally dominant "governing images" (Room, 1978) or "social representations" (Moscovici, 1981, 1988) of various forms of substance use problems, our knowledge of how these vary between various forms of substance use, various population groups, and various cultural contexts is far from comprehensive. Trying to fill this knowledge gap can be considered an important task, not least at a time when addiction is increasingly seen as a global phenomenon (Alexander, 2008). This paper is one in a series of attempts to accomplish this task that have been carried through during the past decade, and compares how lay people in Finland, Sweden, and Canada perceive that individual addiction problems should be understood and handled. In Sweden, data for the analyses have been collected within the research project "The social context of recovery" based at SoRAD, and similar data for Finland and Canada have been collected as part of the work of the international "Theories and Images of Addiction (IMAGES) Consortium", based at the University of Helsinki. More precisely, the paper analyses how respondents in the three countries appraise four different models of handling human and social problems, which are based on attributions of responsibility for, and capacity to solve, these problems. The specific problems focused in the paper are addictions to alcohol, cannabis, "hard" drugs[1], and cigarettes.

\section{Conceptions of addiction and recovery}

Four models of helping and coping. Historically, the debate over how excessive substance use or other deviant behaviours should be understood and handled, has often oscillated between the idea that deviants could and should be seen as "crooks", who should be blamed or punished for their undesired behaviours, or as "victims", whose deviances are outside their personal control, and who are therefore entitled to the environment's commiseration, and to the caring or curing measures that may be available (cf. Sahlin, 1994). However this "badness - illness" dichotomy has repeatedly been demonstrated to be too simplistic when it comes to exploring dominant perceptions or social representations of, for example, substance use problems, which are not only about moral judgements, but also about how problems are explained, and about whether effective remedies are assumed to be available or not, and which are further linked to basic, historical, and structural conditions (e.g. Mäkelä, 1980; Gusfield, 1981; Beckman, 1980). One way of solving this dilemma is to recognize that the answer to the question of how social problems could and should be handled relies on attributions of responsibility in two different respects. By separating attributions about the causation of problems from assumptions about the solution of problems, Brickman et al. (1982) arrive at a model with four basically different orientations to "helping and coping", an obvious advantage of which is that it offers a bridge between a sociocultural and a more clinical perspective on this matter (Blomqvist, 1998). The models have proved to be useful in analysing historical changes in Sweden's way of handling alcohol problems, from the late nineteenth to the late twentieth century (Blomqvist, 1998), and as a theoretical framework in analysing the political chase for a legitimate knowledge base for handling narcotics drugs during the twentieth century in Sweden (Edman and Blomqvist, 2011). They have also been used as a tool for improving "matching" of clients to treatments (Marlatt, 1988).

Previous research. Previous analyses of the national surveys, used for this paper, have shown large differences between the ways in which various addictions are perceived in a certain country, as well as between the ways in which various national populations perceive the same addiction (e.g. Blomqvist, 2009; Holma et al., 2009; Hirschovits-Gerz et al., 2011; Cunningham et al., 2012). Comparisons of lay peoples' and professionals' perceptions have shown relatively few differences (Koski-Jännes et al., 2012a, b; Samuelsson et al., 2013), whereas clients' views have been found to depart more from those of lay people and professionals The comparisons made in previous studies have typically focused the perceived addictiveness of various substances, as well as the rated social severity of, and assumed options to recover from - with or without treatment - various addictions. One study (Koski-Jännes et al., 2012a) compared population, professional, and client support for different ways of managing addictive behaviours in Finland, but no study has this far explored the preferences for different handling models in various countries.

Operationalizing the "Brickman models". Although the "Brickman models" have been found to be useful in exploring how addictions are conceptualized in various contexts (e.g. Blomqvist, 
1998, 2009; Edman and Blomqvist, 2011; Koski-Jännes et al., 2012a), previous studies have also pointed to certain ambiguities. Thus, it is evident that various ways of operationalizing the models will give differing results as concerns the overall support for a certain model, which means that the models are perhaps most useful in comparative studies. Further, the names that Brickman et al. (1982) originally used to characterize their four models may give rise to some misunderstandings. Thus, what these authors name the "moral" model - attributing the cause of as well as the responsibility for and capacity of solving a problem to the individual - has sometimes been interpreted as indicating a moralizing attitude towards the individual. However, since this model actually perceives the individual as strong and resourceful, it might be more illuminating to name it, as we have chosen to do here, the individual model. The model that might rather be associated with moralistic or discriminating attitudes is what Brickman et al. (1982) describe as the "enlightenment model" - that is the idea that the individual could and should be blamed for causing the problem, but that s/he is incapable of solving it without the help of a higher moral authority, which can point them to the true character of their problem, and to the solution that lies in submitting to a higher power. However, since the authority, to which the individual is supposed to submit, may be of both a spiritual and a physical character (as in coercive care for substance abusers), we have chosen in this paper to name this model the disciplinary model (see also Blomqvist, 2004; Edman and Blomqvist, 2011). As concerns what Brickman et al. (1982) refer to as the "medical model" - the idea that the individual could be held responsible neither for the creation nor for the solution of the problem, they underline that this applies not only to medicine proper, but to all interventions - including most kinds of psychotherapy or psychosocial treatment - where the main responsibility of the individual is perceived to be to follow the expert advice that s/he might get from her/his professional helpers. For this reason this model may rather be best described as an expert model (cf. Edman and Blomqvist, 2011). Finally, seeing the individual as a victim of various handicaps or obstacles that have been imposed on them by nature or by society, but still regarding them as capable of solving their problems, given that the environment gives them the necessary support, is in the terms of Brickman et al. (1982) an expression of the "compensatory" model. However, naming it the empowerment model may be a better way to underline the basic idea that the individual is regarded to be entitled to certain help, but that this help is aimed at strengthening her/his own capacity to care for her/himself and her/his fellow citizens. Figure 1 summarizes the four models as they will be used in the present paper (original model names within parentheses).

\section{Aims and research questions}

The aim of the analyses presented in this paper have been to uncover what representative population samples from Sweden, Finland, and Canada perceive to be the proper way of handling, addictions to alcohol, cannabis, "hard" drugs, and cigarettes. The four substances or

Figure 1 Four models of helping and coping

$\underline{\text { Attributions of individual: }}$

Blame:

(responsibility for $\underline{\text { problem causing) }}$

$\underline{\text { High }}$

$\underline{\text { Low }}$

\section{Control}

$\underline{\text { High }} \underline{\text { (capacity for problem }}$ solving)

Individual model

("moral model")

( punishment, rewards)

Empowerment model

("compensatory model")

(support, compensation)
Disciplinary model

("enlightenment model")

(submission, discipline)

Expert model

("treatment model")

(treatment, cure)

Source: After Brickman et al. (1982) 
types of addiction have been chosen since they are common and much discussed, have been subject to rather different public policies, and can be assumed to have rather differing social and cultural "positions" in each of the three countries under study. Comparisons are made of the degree to which respondents from the three countries endorse each of four models of helping and coping, which are illustrated in Figure 1.

\section{Method}

\section{The surveys}

Data for the analyses were gathered in Sweden and Finland, in 2005 and 2007, respectively, by postal surveys to random samples of 2,000 people, drawn from the national census databases. In Canada telephone interviews were conducted, using a random digit dialling approach, by help of a private data collection firm in 2008. The response rates in the three samples were 51 per cent in Sweden, 37 per cent in Finland, and 41 per cent in Canada. All surveys focused nine to 11 potentially addictive substances or behaviours, but as mentioned, the analyses in the present paper are limited to alcohol, cannabis, "hard" drugs, and cigarettes. The key dependent variables used in this paper measured to which extent the respondents attributed the responsibility for acquiring an addiction to these substances/behaviours to the individual and the extent to which the responsibility was attributed to circumstances beyond her/his control, as well as the degree to which respondents saw recovery without treatment (self-change) from an addiction to these substances/behaviours as probable. Based on these questions, preferences for the four handling models, shown in Figure 1, were calculated. In addition, the analyses used data on respondents' personal circumstances, in terms of socio-demographic characteristics, and personal substance use experiences.

\section{Analyses}

The national data sets were first combined and "don't know" responses were recoded as missing data. Differences between countries in relevant aspects were calculated, using bivariate statistics. For categorical variables $\chi^{2}$-tests were used, and for continuous variables groups were compared by ANOVAs with Welch robust tests, and using Tamhane tests for post hoc comparisons. In addition, since the national samples differed somewhat with regard to respondent characteristics, logistic regression analyses were performed, to control to what extent such characteristics contributed in explaining cross-country differences with regard to the preference for different models. The software program used was SPSS 19.0. To control for sampling and attrition bias, Swedish data were corrected for sex, age, income, marital status, and country of origin, whereas the calibration variables in Finland were sex and age, and the calibration variables in Canada, where a different sampling procedure was used, were household size and province size. A combined weight variable has been used in all analyses except for calculating sample sizes. Nonetheless, since this weighting procedure does not account for all potential attrition problems, caution is still warranted in generalizing results to the respective populations.

As mentioned, the construction of preferred handling models for the four addictions has built on cross-tabulating respondents' answers to the questions about the reasons of, or perceived responsibility for acquiring, each addiction, and the rated probability of recovery from each addiction without professional treatment (self-change)[2].

As concerns respondents' answers to the first of these questions, the perceived reasons for acquiring each of the four addictions, it needs to be noted that the Swedish and Finnish surveys used four response alternatives[3], whereas the Canadian telephone interview used three[4]. Thus, to enable comparison, Finnish and Swedish answers also had to be recoded into three categories. Further, and since very few put the blame for getting addicted entirely to circumstances outside the individual's control, this variable has, for the construction of the handling models, been dichotomized between attributing the responsibility to the individual vs seeing it as shared or attributing to other circumstances. Using this dichotomization, the analysis shows that the majority in all national samples perceive this responsibility as shared between the individual and the circumstances for all addictions. The only exception from this rule is Canada, where the most 
common answer is that the responsibility for acquiring an addiction to cigarettes should be attributed largely to the individual. Further, it becomes obvious that addiction to cigarettes is much more often blamed on the smoker her/himself than other addictions are, and that Swedes generally are a bit less inclined to blame the individual for her/his addiction than Finns and Canadians.

The second variable used in constructing the four handling models has been the perceived chances of self-change from the four addictions. Here, the analyses show that only a minority of all respondents rate the probability for self-change as rather or very large, with smoking cessation, particularly in Sweden and Finland, as a clear exception. As for differences between addictions, chances for self-change are also rated much lower in addiction to "hard" drugs than in alcohol and cannabis addiction. On the country level, Canadians are more pessimistic than Finns and Swedes, except as concerns cannabis addiction. Interestingly, Canadians rate the chances for quitting on one's own to be about the same for addictions to cannabis use and cigarettes, whereas Finns and Swedes rate the chances for unaided smoking cessation to be almost twice as large as the chances for self-change from cannabis addiction. As concerns the construction of the handling models, this variable has been dichotomized between "very small" and "rather small" on the one hand, and "neither small or large", "rather large", and "very large" on the other hand[5].

\section{Results \\ Respondents}

Table I displays background data on the survey respondents by country. The Canadian sample has more females than males since the data could not be weighted by sex without losing accuracy in the results. Besides this, the national samples are rather similar with regard to age and education, although differences are clearly significant due to the large sample sizes. As concerns personal substance use experiences, the differences between the three national samples seem largely to mirror differences at the population level, for example in the sense that there are more current risk drinkers in the Finnish sample, and many more current or former cannabis users in the Canadian sample. However, the proportion of current smokers in all samples is considerably higher than what might be expected from topical national statistics on smoking prevalence. This may partly be due to the fact that the prevalence has kept on going down since the surveys were conducted, partly to the fact that the questions did not distinguish between "daily" and "occasional" smokers.

\section{Preferred models of helping and coping}

Preferences for various handling models by addiction. The results of the above-described operationalization of the handling models, when applied to the four types of addictions, and in the three countries, are shown in Figure 2.

As can be seen, the expert model comes out as the dominant one for all addictions except cigarette addictions. Since the main official strategy of handling individual alcohol and drug use problems, in all three countries, clearly is offering psycho-social, psychological and/or

Table I Respondent characteristics

\begin{tabular}{|c|c|c|c|c|}
\hline & Finland $(n=740)$ & Sweden $(n=1,098)$ & Canada $(n=864)$ & $p$ \\
\hline \multicolumn{5}{|l|}{ Demographics } \\
\hline Age (mean, SD) & $45.6(15.9)$ & $44.2(15.7)$ & $46.9(16.7)$ & *** \\
\hline Females & $51.5 \%$ & $49.6 \%$ & $57.6 \%$ & *** \\
\hline College/university education & $27.5 \%$ & $32.9 \%$ & $30.5 \%$ & *** \\
\hline \multicolumn{5}{|l|}{ Substance use experiences } \\
\hline Current risk drinker & $35.3 \%$ & $26.7 \%$ & $23.0 \%$ & 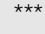 \\
\hline Ever used cannabis & $16.5 \%$ & $15.3 \%$ & $38.4 \%$ & 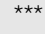 \\
\hline Ever used "hard drugs"* & $4.7 \%$ & $5.3 \%$ & $8.7 \%$ & *** \\
\hline Current smoker & $36.6 \%$ & $30.8 \%$ & $24.0 \%$ & 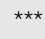 \\
\hline
\end{tabular}


Alcohol addiction
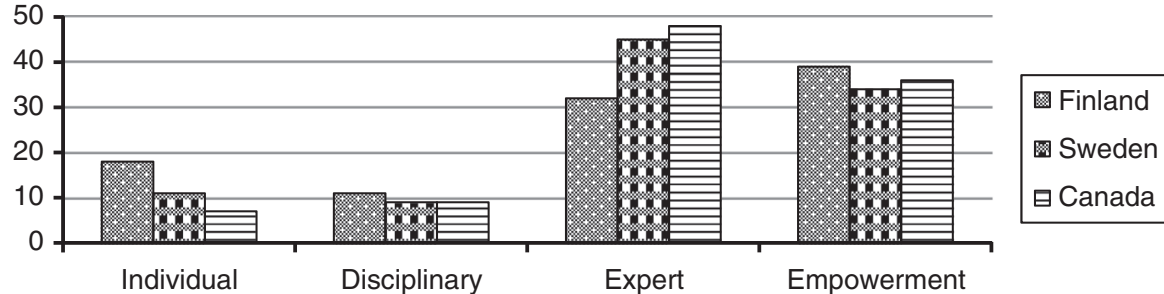

Cannabis addiction

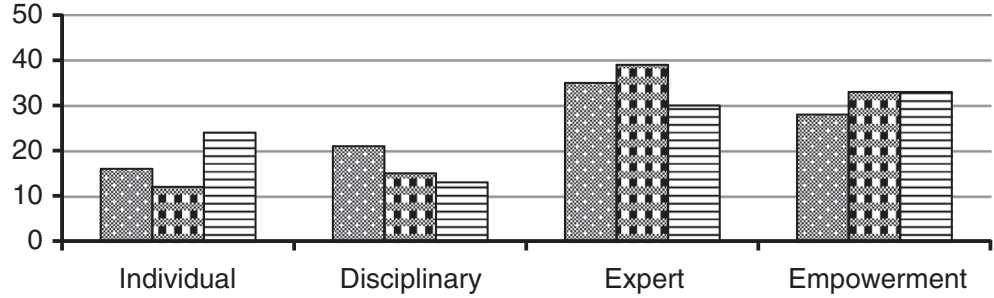

图 Finland

图 Sweden

$\boxminus$ Canada

Addiction to "hard drugs"

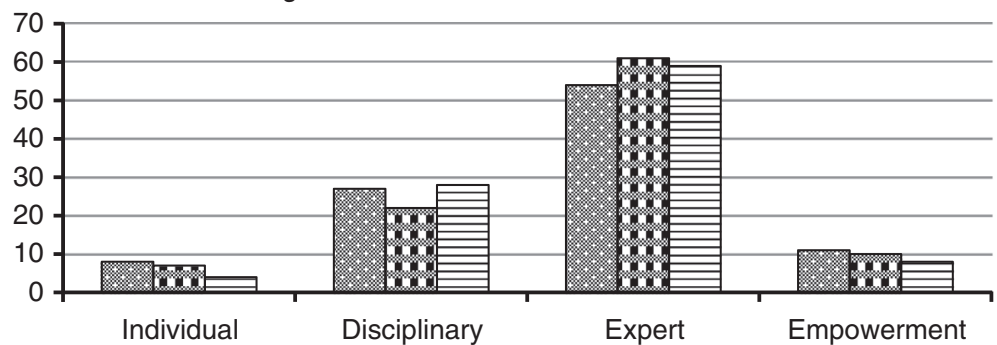

圈 Finland

Sweden

$\boxminus$ Canada

Cigarettes addiction

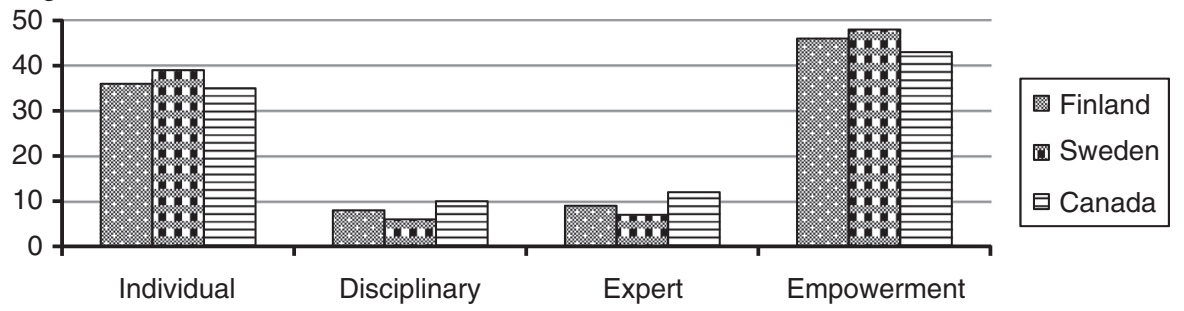

pharmacological treatment, and since most kinds of prevailing treatments can be subsumed under the expert model, this can be claimed to make sense. Seeing the expert model as default also means focusing the main attention in the analysis to the exceptions from this standard. The empowerment model is overall strongest endorsed for addictions to cigarettes, followed by addictions to alcohol and cannabis. The disciplinary model is stronger preferred as a handling model for addiction to "hard" drugs than for other problems, and the individual model has its greatest popularity as concerns handling cigarettes addiction, where it has almost as strong a support as the empowerment model. In addition, the figure shows that there are significant differences between the three countries when it comes to which models are strongest preferred. For example, Finns seem more inclined than other respondents to apply the disciplinary model to addictions to cannabis, whereas Swedes are more inclined than others to endorse the individual and empowerment models in handling addiction to cigarettes. In addition, the expert model for handling alcohol addiction is much less popular in Finland than in the other two countries. As a matter of fact, a series of $\chi^{2}$ analyses shows that all the country differences illustrated in Figure 2 are significant on the 1 per cent level. 
Who perceives which model as adequate for which problem - and where. As briefly discussed above, previous studies have indicated that respondents' perceptions of various addictions can vary not only between substances and countries, but also with respondent characteristics, such as age, sex, and personal substance use experiences (e.g. Blomqvist, 2012; Koski-Jännes et al., 2012b). To get a valid picture of such influences, a number of logistic regressions, with these factors as independent variables, and each of the models as a dependent variable, were conducted for each of the addictions. The results of these analyses are depicted in Table II.

As concerns perceptions of alcohol addiction, the regressions show that the country differences prevail even when controlling for respondent characteristics. Thus, Finns, although they have been shown to rate this problem as more severe than other nationals do (Hirschovits-Gerz et al., 2011), stand out as less supportive than others of the expert model, and as more supportive of the individual and empowerment models, whereas Swedes are less inclined than others to endorse the latter model. In addition, women are - largely due to their lower confidence in self-change - less prone to prefer the individual and empowerment models than men, but more inclined to prefer the expert model. Also age seems to play an independent role in the choice of model, insofar as younger respondents are less inclined than their elders to prefer the individual and disciplinary models, and somewhat more inclined to prefer the empowerment model. Finally, current risk drinkers are less prone to endorse the disciplinary model and more inclined to prefer the empowerment model, than non-drinkers and moderate drinkers.

As for cannabis addiction Finns come out as more inclined than others to prefer the disciplinary model, and as more inclined than Swedes, but less inclined than Canadians to endorse the individual model, even when taking the influence of respondent characteristics into account. Moreover, Swedes' stronger preference for the expert model prevails also in the multivariate context. As for the influence of respondent factors, women believe clearly more than men in the expert model, and less in the individual and empowerment models, whereas younger respondents are more inclined that their elders to support the empowerment model. Further, persons who never used cannabis are more prone than both former and current users to endorse the disciplinary and expert models, and much less supportive of the empowerment model. In addition, ex-users believe more than both non-users and current users in the individual model.

Proceeding to addiction to "hard" drugs, we can also see that the country differences largely prevail in the multivariate context, Canadians being less inclined than others to prefer the individual model, and Swedes being less inclined than others to choose the disciplinary model, and more inclined to endorse the expert model. As regards the influence of respondent characteristics, the expert model is more popular among women than among men, whereas the opposite is true for all the other models. In addition, older respondents are less prone than younger ones to support the expert model, but more prone to support the individual models.

Turning to addiction to cigarettes finally, Canadians have stronger preferences for the disciplinary and expert models and less confidence in the individual and empowerment models than Swedes and Finns. In addition, older respondents believe more in the individual and disciplinary models, and less in the empowerment model than younger respondents. Interestingly, the differences between Sweden and Canada as concerns models of cannabis addiction, are almost inversed compared to the differences as concerns models of smoking. In sum, even if the explained variance is rather modest, the analyses point to at least some interesting differences in the ways in which populations in the three countries understand and prefer to deal with addiction problems.

\section{Discussion \\ Study limitations}

Before proceeding to potential interpretations and conclusions of the results, it needs to be pointed out that the study suffers from some limitations. First, the response rate was low, particularly in the Finnish sample. Even if a weighting procedure was applied to control for attrition bias, this might not have solved all potential attrition problems. Second, as has already been discussed, defining the four models by dichotomizing the two key variables is a somewhat arbitrary process. Although arguments have been put forward for the solution chosen, this means 


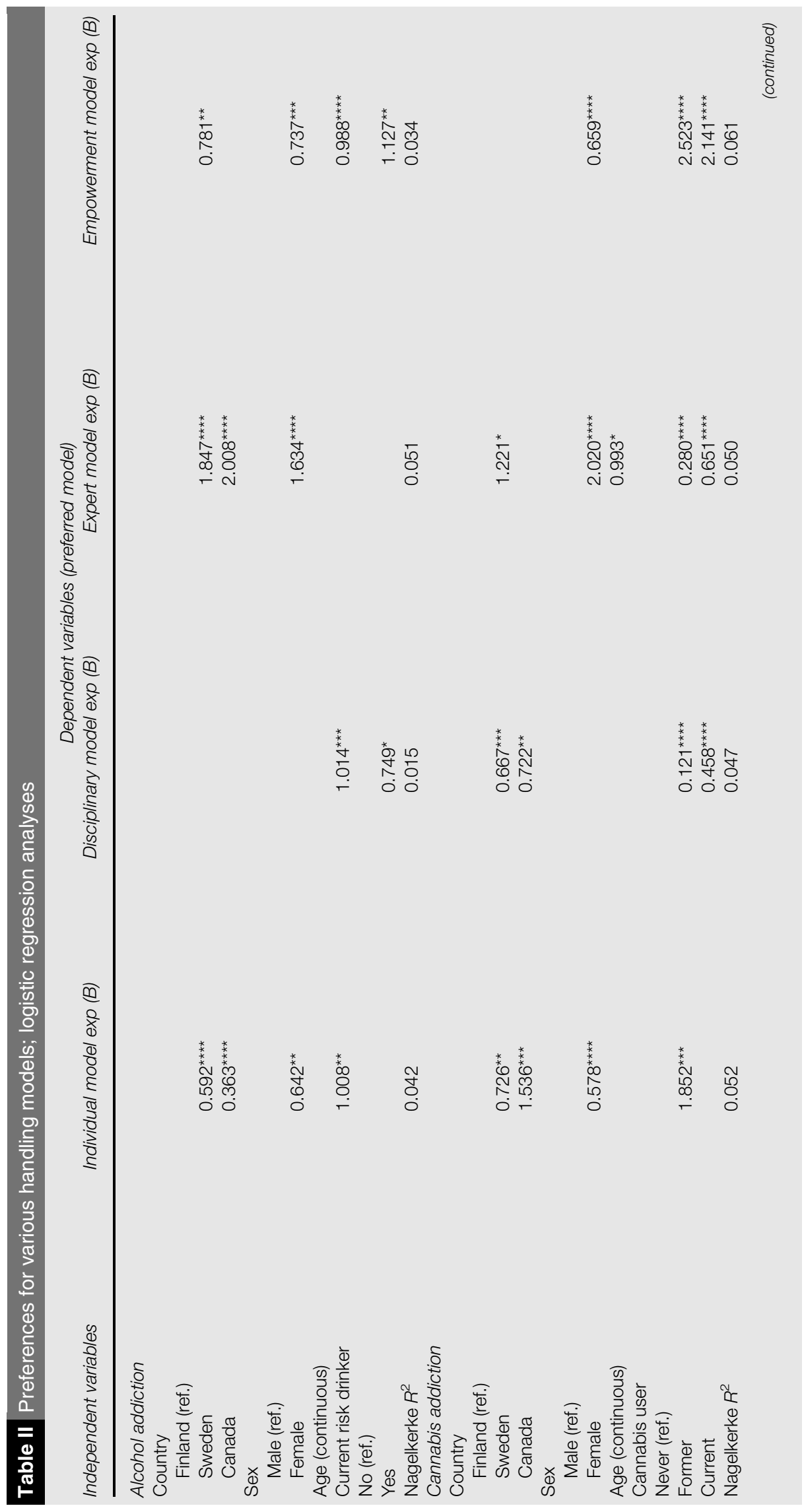




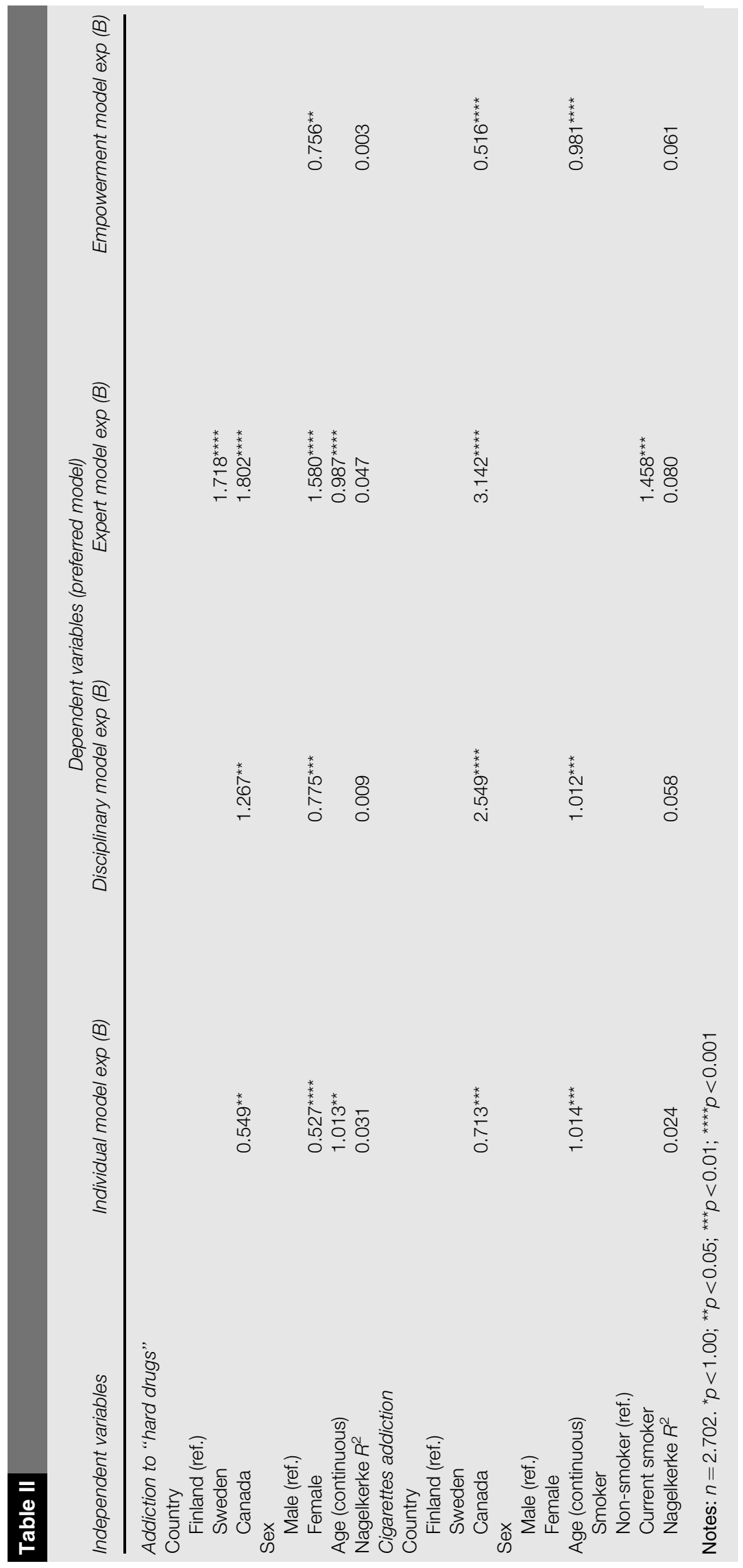

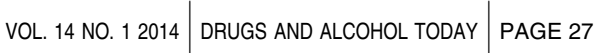


that the support for various models in absolute terms should not be seen as set in stone. Another limitation is that, due to different data collection methods, the wording of some of the questions in the national samples, differs slightly All in all, these limitations warrant caution in generalizing results, particularly in terms of the absolute support for various models, to entire populations. However, comparison of differences between the country samples, which has been the main purpose of this paper, might be claimed to be less sensitive to both these limitations. Finally, recoding "don't know" responses as missing data, which was necessitated since this alternative was available only in the Finnish questionnaire might give rise to a certain bias. However, only a very small minority actually used this option, meaning that this objection could be seen as largely negligible.

\section{How can the differences be interpreted?}

Although the explanatory power of the regression analyses is not particularly strong, the results indicate at least some intriguing differences, both on the group level, and the country level. As for the former, women's generally stronger preferences for the expert model, may to a part be attributed to the fact that women still can be assumed to have - to a greater extent than men been socialized into caring for and worrying about others, and that they have often been shown to be stronger supporters than men of public welfare solutions (Blomqvist, 2012). The influence of age is harder to interpret, but older respondents' tendency to be more supportive of the individual and disciplinary models may be due to a generally harsher view of addiction problems, and a more disillusioned attitude towards the option of quitting among older people (Blomqvist, 2012). The fact that current risk drinkers and cannabis users are more inclined than others to endorse the empowerment model, and less supportive of the disciplinary model[6], may partly be due to a "false hope" of being able to manage on one's own (cf. Polivy and Herman, 2002). At the same time, the fact that also former cannabis users tend to support the empowerment and individual models, should probably rather be seen as mirroring their actual experiences of having been able to quit on their own (cf. Blomqvist, 2012)[7]. Finally, the explanation of the fact that current smokers are more inclined than non-smokers to endorse the expert model seems rather elusive. Tentatively, this result may have to do with the fact that many non-smokers actually quit on their own, but that many current smokers dwell on the hope of the effectiveness of various pharmacological ailments that are increasingly vigorously marketed.

Turning to differences on the country level, these could be interpreted with regard to differing national policies as regards substance use, but also seen as the result of what Sulkunen (2013) refers to as "geographical" differences, including several layers of historically rather stable sentiments and attitudes that not necessarily coincide with national borders. Seen from this perspective, Finns' relatively strong endorsement of the individual and empowerment, and to some extent the disciplinary models, can be seen as an expression of what Sulkunen (2013) refers to as a particular "Finnish individualism" that co-exists with, but at the same time hauls off from, the common Nordic preference for collective welfare solutions that can be assumed to underlie Swedes' - and to some degree Canadians' - preferences for the expert model. However, it can be noted that, as concerns addiction to cannabis, Swedes are more inclined than Canadians to support the expert model, whereas it is the other way around when we look at addictions to cigarettes. As concerns cannabis, this has most probably to do with Sweden's strong stance against all narcotic drugs, and the fact that no official distinction is made between "hard" and "soft" drugs (cf. Blomqvist, 2004), as opposed to a rather strong public opinion in Canada in favour of legalizing cannabis (Kennedy, 2012). As concerns addiction to cigarettes, previous analyses have shown that Swedes tend to regard smoking less as an addiction than as a "bad habit", for which the individual is personally responsible, and which s/he is principally able to quit (Blomqvist, 2009, 2012). Possibly Canadians are, perhaps due to larger media attention, and a stronger influence from the American "disease" notion of addiction, and the Surgeon General's (The Reports of the Surgeon General, 1988) description of smoking as an expression of "nicotine dependence", more inclined to see smoking as a problem, for which society should take responsibility.

Finally, the fact that Finns are less inclined than others to endorse the expert model for handling addictions to "hard drugs", may have to do with such addictions being relatively foreign to the Finnish society (Partanen et al., 2007). Swedes' larger inclination to support the expert model in handling such addictions, and Canadians' lower propensity to support the individual model in comparison to Finns, may reflect Swedes' and Canadians' trust in welfare solutions, as well as

PAGE 28 DRUGS AND ALCOHOL TODAY $\mid$ VOL. 14 NO. 12014 
Finnish individualism and "sisu" (cf. Hirschovits-Gerz et al., 2011), and Sweden's ambitions to create a "drug-free society".

\section{Potential implications}

Overall, this study has shown that cultural and contextual factors, as well as personal circumstances and experiences, are likely to influence peoples' way of understanding, and preferred ways of handling, various addiction problems. Even if the aim of this paper has not been to lay the ground for policy deliberations and decisions, there are at least some potential implications of these findings. Thus, considering the many ways in which the governing images or prevailing social representations may influence the lives of those concerned, knowledge of these factors and how they vary between contexts and populations groups, may be claimed to be important in designing realistic, credible, and effective help strategies. As concerns future research in this area, one implication would be to complement survey research with studies using qualitative methods, such as focus group interviews, to test the validity of survey results, and to get a deeper understanding of how differing under-standings are formed in various social and cultural contexts.

\section{Notes}

1. That is, other narcotics-classified drugs than cannabis, predominantly heroin and amphetamine.

2. The first of these questions read in English: "In general, do you think it is mainly the person's fault when they are addicted to (Substance A) or do you think the addiction stems from circumstances beyond their control"? The second question read: "What do you think the chances are that a person addicted to (substance A) can fix their addiction on their own, without getting any treatment"?

3. Entirely the individual - mostly the individual - mostly other circumstances - entirely other circumstances.

4. Entirely/mostly individual - shared - entirely/mostly other circumstances.

5. This dichotomization can be claimed to make sense not least since the probability for self-change is commonly rather strongly underrated (cf. Klingemann and Sobell, 2007).

6. And in the case of cannabis, also the expert model.

7. Thus, the hope among current users to be able to quit without help may not in all cases be "false" after all.

\section{References}

Alexander, B. (2008), The Globalization of Addiction. A Study in Poverty of the Spirit, Oxford University Press, Oxford.

Beckman, S. (1980), Kärlek på tjänstetid. Om amatörer och professionella inom vården, Arbetslivscentrum, Stockholm.

Blomqvist, J. (1998), "Beyond treatment. Widening the approach to alcohol problems and solutions", Studies in Social Work No. 13, Stockholm University, Stockholm.

Blomqvist, J. (2004), "Sweden's 'war on drugs' in the light of addicts' own experiences", in Rosenqvist, P., Blomqvist, J. et al. (Eds), Addiction and Life Course, NAD Publication No. 44, NAD, Helsinki, pp. 139-72.

Blomqvist, J. (2009), "What is the worst thing you could get hooked on? Popular images of addiction problems in contemporary Sweden", Nordic Studies on Alcohol and Drugs, Vol. 26 No. 4, pp. 373-98.

Blomqvist, J. (2012), "Perceptions of addiction and recovery in Sweden: the influence of respondent characteristics", Addiction Research and Theory, Early Online, Vol. 20 No. 53, pp. 435-66.

Brickman, P., Rabinovitz, V.C., Karuza, J., Coates, D., Cohn, E. and Kisser, L. (1982), "Models of helping and coping", American Psychologist, Vol. 37 No. 4, pp. 368-84.

Cunningham, J., Blomqvist, J., Koski-Jännes, A. and Raitasalo, K. (2012), "Societal images of Cannabis use: comparing three countries", Harm Reduction Journal, Vol. 9 No. 21, pp. 21-3.

Edman, J. and Blomqvist, J. (2011), "Jakten på den verksamma vården”, in Olsson, B. et al. (Eds), Narkotika. Om problem och politik, Norstedts Juridik, Stockholm, pp. 161-85.

Gusfield, J.R. (1981), The Culture of Public Problems: Drinking-Driving and the Symbolic Order, University of Chicago Press, Chicago, IL.

Hacking, I. (1999), The Social Construction of What? Harvard University Press, London.

VOL. 14 NO. 12014 DRUGS AND ALCOHOL TODAY $\mid$ PAGE 29 
Hirschovits-Gerz, T., Holma, K., Koski-Jännes, A., Raitasalo, K., Blomqvist, J., Cunningham, J.A. and Pervova, I. (2011), "Is there something peculiar about Finnish views on alcohol addiction? - a cross-cultural comparison between four northern populations", Research on Finnish Society, Vol. 4 No. 201, pp. 41-54.

Holma, K., Koski-Jännes, A., Raitasalo, K., Blomqvist, J., Pervova, I. and Cunningham, J. (2009), "Perceptions of addictions as societal problems in Canada, Sweden, Finland and Russia", European Addiction Research, Vol. 17 No. 2, pp. 106-12.

Kennedy, M. (2012), "Most canadians firmly in favour of decrinializing marijuana: poll", available at: http:// news.nationalpost.com/2012/07/02/most-canadians-firmly-in-favour-of-decriminalizing-marijuana-poll/

Klingemann, H. and Sobell, L.C. (Eds) (2007), Promoting Self-Change from Addictive Behaviors, Springer, New York, NY.

Koski-Jännes, A., Hirschovits-Gerz, T. and Pennonen, M. (2012a), "Population, professional, and client support for different models of managing addictive behaviors", Substance Use \& Misuse, Vol. 47 No. 3, pp. 296-308.

Koski-Jännes, A., Hirschovits-Gerz, T., Pennonen, M. and Nyyssönen, M. (2012b), "Population, professional and clients' views on dangerousness of various addictions on individual and society", Nordic Studies on Alcohol and Drugs, Vol. 29 No. 2, pp. 139-54.

Mäkelä, K. (1980), "What can medicine properly take on?", in Edwards, G. and Grant, M. (Eds), Alcoholism Treatment in Transition, Croom Helm, London, pp. 225-33.

Marlatt, G.A. (1988), "Matching clients to treatment. Treatment models and stages of change", in Donovan, D.M. and Marlatt, G.A. (Eds), Assessment of Addictive Behaviors, Guilford Press, New York, NY, pp. 474-83.

Moscovici, S. (1981), "On social representations", in Forgas, J.P. (Ed.), Social Cognition, Academic Press, London, pp. 181-209.

Moscovici, S. (1988), "Notes towards a description of social representations", European Journal of Social Psychology, Vol. 18 No. 3, pp. 211-50.

Partanen, P., Hakkarainen, P., Hankilanoja, A., Kuussaari, K., Rönkä, S., Salminen, M., Seppälä, T. and Virtanen, A. (2007), "Amfetamiinien ja opiaattien ongelmakäytön yleisyys Suomessa 2005. Prevalence of amphetamine and opiate problem use in Finland 2005", Yhteiskuntapolitiikka, Vol. 72 No. 5, pp. 553-61.

Polivy, J. and Herman, C.P. (2002), "If at first you don't succeed-false hopes of self-change", American Psychologist, Vol. 57 No. 9, pp. 677-89.

(The) Reports of the Surgeon General (1988), "The health consequences of smoking: nicotine addiction", a report of the Surgeon General, Center for Health Promotion and Education, Office on Smoking and Health United States, Public Health Service, Office of the Surgeon General. US Government Printing Office, Washington, DC.

Room, R. (1978), Governing Images of Alcohol and Drug Problems, University of California, Berkeley, CA.

Sahlin, I. (1994), "Den kluvna klienten”, Socialvetenskaplig Tidskrift, Vol. 4 No. 4, pp. 303-24.

Samuelsson, E., Blomqvist, J. and Christophs, I. (2013), "Addiction and recovery-conceptions among professionals in the Swedish treatment system”, Nordic Studies on Alcohol and Drugs, Vol. 26 No. 4, pp. 373-98.

Sulkunen, P. (2013), "Geographies of addiction", Nordic Studies of Alcohol and Drugs, Vol. 30 Nos 1/2, pp. 7-12.

\section{Corresponding author}

Professor Jan Blomqvist can be contacted at: jan.blomqvist@sorad.su.se

To purchase reprints of this article please e-mail: reprints@emeraldinsight.com Or visit our web site for further details: www.emeraldinsight.com/reprints 